\title{
Breast Cancer cN3 TNM Finding v7
}

National Cancer Institute

\section{Source}

National Cancer Institute. Breast Cancer cN3 TNM Finding v7. NCI Thesaurus. Code C88370.

Breast cancer with metastases in ipsilateral infraclavicular (level III) axillary lymph node(s) with or without level I, II axillary lymph node involvement; or in clinically detected ipsilateral internal mammary lymph node(s) with clinically evident level I, II axillary lymph node metastases; or metastases in ipsilateral supraclavicular lymph node(s) with or without axillary or internal mammary lymph node involvement. (from AJCC 7th Ed.) 